\title{
Leveraging Nanocrystal HKUST-1 in Mixed-Matrix Membranes for Ethylene/Ethane Separation
}

\author{
Chong Yang Chuah ${ }^{1} \mathbb{D}$, S.A.S.C. Samarasinghe ${ }^{1}$, Wen $\mathrm{Li}^{2}$, Kunli Goh ${ }^{1, *} \mathbb{D}$ and Tae-Hyun Bae ${ }^{3, *}$ \\ 1 Singapore Membrane Technology Centre, Nanyang Environment and Water Research Institute, \\ Nanyang Technological University, Singapore 637141, Singapore; chongyang.chuah@ntu.edu.sg (C.Y.C.); \\ samarasi001@e.ntu.edu.sg (S.A.S.C.S.) \\ 2 School of Chemical and Biomedical Engineering, Nanyang Technological University, Singapore 637459, \\ Singapore; liwe0025@e.ntu.edu.sg \\ 3 Department of Chemical and Biomolecular Engineering, Korea Advanced Institute of Science and \\ Technology, Daejeon 34141, Korea \\ * Correspondence: gohkunli@ntu.edu.sg (K.G.); thbae@kaist.ac.kr (T.-H.B.)
}

Received: 28 March 2020; Accepted: 14 April 2020; Published: 16 April 2020

\begin{abstract}
The energy-intensive ethylene/ethane separation process is a key challenge to the petrochemical industry. HKUST-1, a metal-organic framework (MOF) which possesses high accessible surface area and porosity, is utilized in mixed-matrix membrane fabrication to investigate its potential for improving the performance for $\mathrm{C}_{2} \mathrm{H}_{4} / \mathrm{C}_{2} \mathrm{H}_{6}$ separation. Prior to membrane fabrication and gas permeation analysis, nanocrystal HKUST-1 was first synthesized. This step is critical in order to ensure that defect-free mixed-matrix membranes can be formed. Then, polyimide-based polymers, ODPA-TMPDA and 6FDA-TMPDA, were chosen as the matrices. Our findings revealed that $20 \mathrm{wt} \%$ loading of HKUST- 1 was capable of improving $\mathrm{C}_{2} \mathrm{H}_{4}$ permeability $(155 \%$ for ODPA-TMPDA and $69 \%$ for 6FDA-TMPDA) without excessively sacrificing the $\mathrm{C}_{2} \mathrm{H}_{4} / \mathrm{C}_{2} \mathrm{H}_{6}$ selectivity. The $\mathrm{C}_{2} \mathrm{H}_{4}$ and $\mathrm{C}_{2} \mathrm{H}_{6}$ diffusivity, as well as solubility, were also improved substantially as compared to the pure polymeric membranes. Overall, our results edge near the upper bound, confirming the effectiveness of leveraging nanocrystal HKUST- 1 filler for performance enhancements in mixed-matrix membranes for $\mathrm{C}_{2} \mathrm{H}_{4} / \mathrm{C}_{2} \mathrm{H}_{6}$ separation.
\end{abstract}

Keywords: $\mathrm{C}_{2} \mathrm{H}_{4} / \mathrm{C}_{2} \mathrm{H}_{6}$ separation; HKUST-1; gas permeation; solubility; diffusivity

\section{Introduction}

Olefin is one of the most important building blocks in the petrochemical industry. One example is ethylene $\left(\mathrm{C}_{2} \mathrm{H}_{4}\right)$. The global annual production of ethylene reached to almost 150 million tons in 2016, and is projected to exceed 200 million tons in the year of 2020 [1,2]. However, looking forward, the need for future energy security through renewable energies, the measurable socio-economic impact due to climate change, and the inexorable call for a circular economy, are likely to drive a transition in the petrochemical industry to generate value-creating opportunities to deal with the shrinking demand for ethylene, and an impending slower market growth [2,3]. Despite that, ethylene remains as an active pharmaceutical ingredient and is used in the production of polymers such as polyethylene and polyvinyl chloride [4-6]. Ethylene (alkene in general) is typically produced via hydrocarbon cracking (either from naphtha in crude oil or ethane from natural gas). There are also efforts in producing ethylene through environmental-friendly means, such as ethylene biosynthesis in biorefinery [7-9]. However, doing so requires a complex coalition of both the petrochemical and biorefining industries, which will involve challenges including finding affordable feedstock access, enabling capabilities for industrial-scale commercialization and value-chain integration, as well as soliciting stable and 
supportive regulations by the government $[10,11]$. Regardless of how the industry eventually evolves, light hydrocarbon separation, such as the separation of ethylene from its paraffin counterpart, ethane $\left(\mathrm{C}_{2} \mathrm{H}_{6}\right)$, is deemed necessary after contaminants removal to give the precursor [12,13]. Essentially, ethylene/ethane $\left(\mathrm{C}_{2} \mathrm{H}_{4} / \mathrm{C}_{2} \mathrm{H}_{6}\right)$ separation is critical as the purity of the ethylene precursor directly influences the quality of the high-value commercial end-products.

In a typical petrochemical process where high purity ethylene feed is desired, a high-pressure (c.a. 23 bar) cryogenic distillation process that operates at low temperature $\left(-160^{\circ} \mathrm{C}\right)$ is necessary to separate ethylene from ethane at the desired purity in view of their close melting and boiling points. This process is energy intensive, with $75-85 \%$ of the total cost expected to be siphoned out from the ethylene production [1,12,14-17]. Adsorptive separation via pressure swing adsorption (PSA) is also energy-intensive as it requires additional energy supply to regenerate the saturated adsorbents for enabling a repetitive adsorption-desorption cycling process. In comparison, gas separation membrane technology is comparatively low cost and energy efficient as the separation is carried out without any phase change and usually under ambient conditions [18-23]. Polymeric membranes are at the core of this technology, considering their high mechanical stability and ease of processability. Nonetheless, conventional polymeric membranes are hampered by an inevitable permeability-selectivity trade-off given that solution-diffusion is the main separation mechanism [24-29]. Apart from this, inorganic membranes, such as those based on pure zeolites and metal-organic frameworks (MOFs), are typically high-performing but hampered by their poor scalability potential [30]. Beyond membrane performances, other real-life challenges, such as effects of high temperatures and pressures, presence of moisture in the feed gas and impurities such as $\mathrm{H}_{2} \mathrm{~S}$ that are damaging to the membranes, must be addressed to realize industrial applications [31-37]. However, in this work, our aim is to develop mixed-matrix membranes, which amalgamate the merits of both polymeric and inorganic membranes, to achieve enhanced $\mathrm{C}_{2} \mathrm{H}_{4} / \mathrm{C}_{2} \mathrm{H}_{6}$ separation.

Mixed-matrix membranes achieve enhanced separation performance of the polymeric matrices by incorporating nanoporous materials as fillers to provide pathways of higher diffusion coefficient to engineer the transport properties of the membranes [35,38-40]. To date, MOF is an attractive filler material for mixed-matrix membranes for gas separation process, owing to its large pore volume and accessible surface area for increasing gas diffusivity. On the other hand, facile post- and pre-synthetic functionalization of MOFs can enhance the affinity of the gas molecules to the filler materials, leading to an improvement in gas solubility [36,37,41,42]. More importantly, MOFs is more compatible with the organic polymer matrix in view of the moieties in the frameworks that are similarly organic in nature. This eliminates the need for compatibilizers to enhance the interfacial morphology between the polymer and filler $[43,44]$.

For these reasons, we have chosen to focus on HKUST-1 to investigate its potential utility as a filler for mixed-matrix membrane for $\mathrm{C}_{2} \mathrm{H}_{4} / \mathrm{C}_{2} \mathrm{H}_{6}$ separation. HKUST-1 possesses large square pores of $9 \times 9 \AA$ and, more importantly, unsaturated metal sites that favor interaction towards the $\pi$-electron system ( $\mathrm{sp}^{2}$ hybridized) of the ethylene molecules. In comparison with other well-reported MOFs, such as IRMOF-8, ZIF-7, and ZIF-8, which do not contain these strong metal sites, favorable interaction with $\mathrm{C}_{2} \mathrm{H}_{4}$ is improbable, resulting in less competitive $\mathrm{C}_{2} \mathrm{H}_{4} / \mathrm{C}_{2} \mathrm{H}_{6}$ separation [45-47]. Furthermore, as compared to MOF-74, which contains open metal sites, HKUST-1 is generally more tolerable towards water vapor and humidity, rendering it more practical for mixed-matrix membrane fabrication $[48,49]$. At present, micron-sized HKUST-1 is commercially available under the tradename Basolite C300 (produced by BASF, Ludwigshafen, Germany). Nonetheless, the particle size is too large for membrane fabrication. Hence, we chose to synthesis nanocrystals of HKUST-1 to increase its effectiveness as a nanoporous filler for the development of mixed-matrix membrane [50].

In this work, $\mathrm{C}_{2} \mathrm{H}_{4} / \mathrm{C}_{2} \mathrm{H}_{6}$ separation performance of mixed-matrix membranes is conducted using a 50/50 mixture gas. Nanocrystal HKUST-1 was incorporated into two glassy polymers, namely ODPA-TMPDA and 6FDA-TMPDA (The abbreviations of these polymers will be explained in Section 2.1). These polymers were selected for its higher $\mathrm{C}_{2} \mathrm{H}_{4}$ permeability as compared to 
commercially available glassy polymers (e.g., Matrimid ${ }^{\circledR}$, polysulfone, and Ultem ${ }^{\circledR} / \mathrm{P} 84$ ) $[32,33,51,52]$. Our results showed that, with the addition of HKUST-1 nanocrystals, a clear improvement in $\mathrm{C}_{2} \mathrm{H}_{4}$ permeability of the membranes can be observed. Comprehensive analyses $\left(\mathrm{C}_{2} \mathrm{H}_{4}\right.$ and $\mathrm{C}_{2} \mathrm{H}_{6}$ solubility and diffusivity) on the addition of HKUST-1 nanocrystals in polymeric membrane were evaluated to elucidate the possible reasons behind the improved performances.

\section{Materials and Methods}

\subsection{Materials}

2,4,6-trimethyl-m-phenylenediamine (TMPDA), 4,4'-(hexafluoroisopropylidene)diphthalic anhydride (6FDA), 4,4'-oxydiphthalic anhydride (ODPA), acetic anhydride ( $\left.\mathrm{Ac}_{2} \mathrm{O}\right)$, copper(II) nitrate trihydrate $\left(\mathrm{Cu}\left(\mathrm{NO}_{3}\right)_{2} \cdot 3 \mathrm{H}_{2} \mathrm{O}\right), \mathrm{N}$-methyl-2-pyrrolidone (NMP), triethylamine (TEA), and trimesic acid $\left(\mathrm{C}_{9} \mathrm{H}_{6} \mathrm{O}_{6}\right)$ were purchased from Sigma Aldrich (Singapore). Absolute ethanol, dimethylacetamide (DMAc), methanol, and chloroform were purchased from VWR (Singapore). For the synthesis of 6FDA-TMPDA, the respective monomers were purified first via a sublimation process (under vacuum). All other chemicals and reagents were used as received.

\subsection{Synthesis of Nanocrystal HKUST-1}

Nanocrystal HKUST-1 were developed based on the method use in the literature as indicated elsewhere [53]. First, addition of $\mathrm{Cu}\left(\mathrm{NO}_{3}\right)_{2} \cdot 3 \mathrm{H}_{2} \mathrm{O}(1.2 \mathrm{~g})$ was conducted in a glass vial that contains absolute ethanol $(20 \mathrm{~mL})$. Next, $\mathrm{C}_{9} \mathrm{H}_{6} \mathrm{O}_{6}(0.6 \mathrm{~g})$ was added and agitated at room temperature with relative humidity of $60-70 \%$ for 1 day. Vacuum filtration was used to recover the HKUST-1 nanocrystals under extensive washing by copious amounts of ethanol:water mixture in the volume ratio of 1:1.

\subsection{Synthesis of ODPA-TMPDA Polymer}

The ODPA-TMPDA polymer (Figure 1) was synthesized under an inert atmosphere based on the procedures as elaborated below $[39,54]$. First, TMPDA $(1.63 \mathrm{~g})$ was added into a flask, which was followed by the incorporation of DMAc $(20.0 \mathrm{~g})$. The solution was vigorously stirred before the addition of ODPA ( $3.36 \mathrm{~g}$ ) into the resulting mixture. The mixture was then stirred for 1 day to obtain a viscous polyamic acid solution. Next, $4.39 \mathrm{~g}$ of TEA and $4.44 \mathrm{~g}$ of $\mathrm{Ac}_{2} \mathrm{O}$ were added to the solution to initiate an imidization process. The solution was allowed to agitate for an additional of 1 day before it was poured slowly into a beaker that contained absolute ethanol so as to precipitate out the product polymer. The product polymer was washed several times with fresh absolute ethanol before drying under vacuum at $160^{\circ} \mathrm{C}$ overnight.

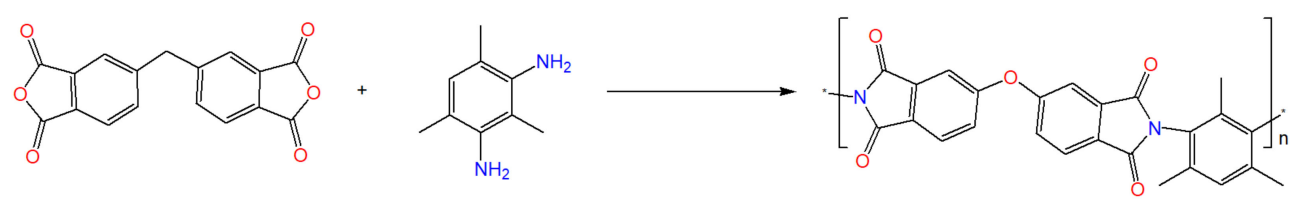

Figure 1. Reaction scheme of ODPA-TMPDA synthesis.

\subsection{Synthesis of 6FDA-TMPDA Polymer}

Separately, the 6FDA-TMPDA polymer (Figure 2) was developed using the method as described below [19]. Similar to ODPA-TMPDA, the whole synthesis was conducted in an inert atmosphere. 6FDA $(0.44 \mathrm{~g})$ was first added into a round-bottom flask. NMP $(1.6 \mathrm{~mL})$ and TMPDA $(0.15 \mathrm{~g})$ was then gradually added. The mixture was stirred for about $30 \mathrm{~min}$ before the solution was diluted further with $9.6 \mathrm{~mL}$ of NMP. 5-h agitation of the mixture was conducted to ensure that the viscous polyamic acid solution can be formed. This was followed by the imidization process, with the addition of TEA $(0.20 \mathrm{~g})$ and $\mathrm{Ac}_{2} \mathrm{O}(0.82 \mathrm{~g})$. The process is allowed to go to completion by mixing for $20 \mathrm{~h}$. The solution was 
finally precipitated with methanol, where the polymer was washed several times with fresh methanol before drying under vacuum at $160^{\circ} \mathrm{C}$ overnight.

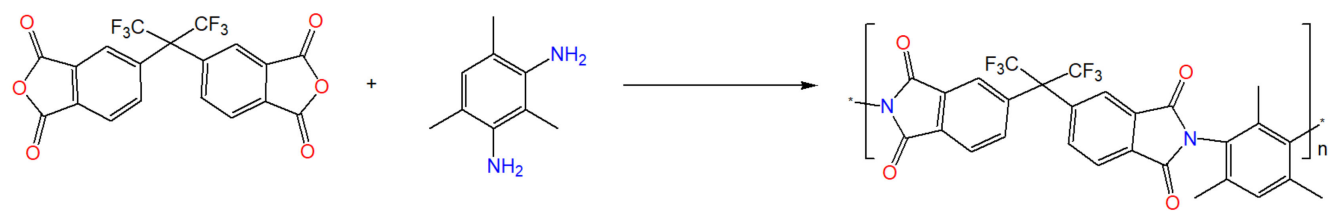

Figure 2. Reaction scheme of 6FDA-TMPDA synthesis.

\subsection{Membrane Fabrication}

The fabrication of dense mixed-matrix membranes was adopted via solution casting approach. First, $0.5 \mathrm{~g}$ of nanocrystal HKUST-1 was dispersed in $3 \mathrm{~mL}$ chloroform. The potential agglomeration of nanocrystal HKUST-1 was minimized with the addition of sonication horn for 5-min duration (Qsonica, Q125, Newtown, CT, USA). After the sonication completes, the polymers were added into the solution and the resulting mixture was agitated overnight. Next, the dope solution was poured onto a flat glass plate and cast into a continuous film. The thickness of the membrane was controlled with the use of a casting knife. The membranes were cast inside a glove bag to ensure a casting environment filled with chloroform vapor so as to inhibit rapid solvent evaporation. After providing sufficient evaporation time for phase inversion, a vacuum oven was used to anneal the resulting membranes at $160{ }^{\circ} \mathrm{C}$ for $24 \mathrm{~h}$.

\subsection{Characterization}

\subsubsection{Characterization of Nanocrystal HKUST-1}

NOVATouch LX2 (volumetric gas sorption analyzer, Quantachrome, Boynton Beach, FL, USA) was utilized in this study to investigate the $\mathrm{C}_{2} \mathrm{H}_{4}$ and $\mathrm{C}_{2} \mathrm{H}_{6}$ adsorption properties of the nanocrystal HKUST-1. The nanocrystal HKUST-1 was first outgassed at $160{ }^{\circ} \mathrm{C}$ for 1 day under high vacuum to remove any potential residual solvents in the nanocrystal HKUST-1. $\mathrm{C}_{2} \mathrm{H}_{4}$ and $\mathrm{C}_{2} \mathrm{H}_{6}$ isotherms were measured in the range of $0-1$ bar at 25 and $35^{\circ} \mathrm{C}$. Water circulator is used to ensure that the temperature does not fluctuate during the measurement. The isotherms of $\mathrm{C}_{2} \mathrm{H}_{4}$ and $\mathrm{C}_{2} \mathrm{H}_{6}$ were fitted accordingly with dual-site and single-site Langmuir equations (Equations (1) and (2)) [55].

$$
\begin{gathered}
q=\frac{q_{s a t, 1} b_{1} p}{1+b_{1} p}+\frac{q_{s a t, 2} b_{2} p}{1+b_{2} p} \\
q=\frac{q_{s a t} b_{1} p}{1+b_{1} p}
\end{gathered}
$$

where $q_{\text {sat }, 1}, q_{\text {sat }, 2}=$ saturation loading in mmol g ${ }^{-1}, b_{1}, b_{2}=$ Langmuir constant in bar $^{-1}, p=$ pressure in bar, and $q=$ amount of $\mathrm{C}_{2} \mathrm{H}_{4}$ and $\mathrm{C}_{2} \mathrm{H}_{6}$ adsorption in $\mathrm{mmol} \mathrm{g}{ }^{-1}$. The mixture-gas selectivity (Ideal Adsorbed Solution Theory, IAST) was used to determine the $\mathrm{C}_{2} \mathrm{H}_{4} / \mathrm{C}_{2} \mathrm{H}_{6}$ selectivity of the nanocrystal HKUST-1 [56], as exemplified in Equation (3):

$$
\text { Selectivity }=\frac{x_{1} / x_{2}}{y_{1} / y_{2}}
$$

where $x_{1}, x_{2}=$ mole fractions of the adsorbed phase, and $y_{1}, y_{2}=$ mole fraction of the gas phase. Isosteric heat of adsorption, $-Q_{s t}$ was determined from the Clausius-Clapeyron equation by measuring the $\mathrm{C}_{2} \mathrm{H}_{4}$ and $\mathrm{C}_{2} \mathrm{H}_{6}$ isotherms of nanocrystal HKUST- 1 at 25 and $35^{\circ} \mathrm{C}$ [57-59].

$$
-Q_{s t}=R T^{2}\left(\frac{\partial \ln p}{\partial T}\right)_{q}
$$


In this expression, $R=$ molar gas constant, $T=$ temperature in $\mathrm{K}, p=$ pressure in bar and $q=$ adsorbed amount in $\mathrm{mmol} \mathrm{g}^{-1}$, which can be obtained either from the dual-site or single-site Langmuir equation. Besides, volumetric gas sorption analyzer was used to measure $\mathrm{N}_{2}$ physisorption at $-196{ }^{\circ} \mathrm{C}(77 \mathrm{~K})$ to determine the porosity properties of the nanocrystal HKUST-1, for which similar activation condition as elaborated above was utilized. A D2 phaser (X-ray diffraction, Bruker, Billerica, MA, United States) was used to verify the crystallinity of the nanocrystal HKUST-1 using a laser beam (with a $\mathrm{CuK} \alpha$ radiation, $0.154 \mathrm{~nm}$ ). At room temperature, the analysis condition (step size of $0.02^{\circ}$ and $2 \theta$ from 5 to $40^{\circ}$ ) was set. Field-emission scanning electron microscope (FESEM, JSM6701, JEOL, Akishima, Japan), which is set at $5 \mathrm{kV}$ acceleration voltage, was used to investigate the structural morphology of nanocrystal HKUST-1. The particle size distribution (mean and standard deviation) of nanocrystal HKUST-1 was calculated with the aid of image analysis tool (Nano Measure). The thermal stability of nanocrystal HKUST-1 was measured with the use of a thermogravimetric analyzer (TGA, SDT Q600, TA instrument, New Castle, DE, United States), which was conducted under a temperature scan of 40 to $800{ }^{\circ} \mathrm{C}$ at a ramping rate of $10^{\circ} \mathrm{C} \mathrm{min}{ }^{-1}$. Nitrogen gas is used as purging gas at a flow rate of $100 \mathrm{~mL} \mathrm{~min}^{-1}$. Change in mass per unit temperature $(d m / d T)$ was calculated to investigate the thermal behavior of nanocrystal HKUST-1.

\subsubsection{Characterization of Mixed-Matrix Membranes}

FESEM (JSM6701, JEOL, Akishima, Japan) at $5 \mathrm{kV}$ acceleration voltage was used to determine the cross-sectional morphology of the mixed-matrix membranes. The membranes were fractured under liquid nitrogen prior to the gold coating process. Fourier transform-infrared spectroscopy (FT-IR, PerkinElmer, Spectrum One, Waltham, MA, USA) was used to understand the functional groups of the pure polymeric membrane. The measurement was conducted in the range of 4000 to $450 \mathrm{~cm}^{-1}$ with a $4 \mathrm{~cm}^{-1}$ resolution. TGA (SDT Q600, TA instrument, New Castle, DE, USA) was used to determine the thermal properties of both mixed-matrix and polymeric membranes. Similarly, $d m / d T$ was also calculated to investigate the behavior of membranes developed in this work. Temperature scan (40 to $800{ }^{\circ} \mathrm{C}$ ) and ramping rate at $10{ }^{\circ} \mathrm{C} \mathrm{min}^{-1}$ (together with the purging of pure nitrogen at $100 \mathrm{~mL} \mathrm{~min}^{-1}$ ) were set. An analytical balance with a density kit feature (Mettler Toledo, ME204, Columbus, $\mathrm{OH}$, USA) was utilized to determine the respective density of mixed-matrix and polymeric membranes. This value was calculated by measuring the sample in both auxiliary liquid (ethanol) and air using Archimedes' principle.

\subsubsection{Mixture Gas Permeation Analysis}

Mixture gas permeation analysis was measured by using a permeation setup from GTR Tec Corporation (constant pressure-variable volume system). The ethylene/ethane mixture $\left(\mathrm{C}_{2} \mathrm{H}_{4} / \mathrm{C}_{2} \mathrm{H}_{6}=50: 50 \mathrm{vol} \%\right)$ and helium gas (He, 99.9995\%) utilized in this set-up were obtained from Air Liquide, Singapore Pte Ltd. This composition of the $\mathrm{C}_{2} \mathrm{H}_{4} / \mathrm{C}_{2} \mathrm{H}_{6}$ mixture has been widely used as an initial screening for the preliminary investigation of the separation performance of membranes and porous materials [60-62]. Hence, we have adopted the same $\mathrm{C}_{2} \mathrm{H}_{4} / \mathrm{C}_{2} \mathrm{H}_{6}$ mixture composition in this work. To measure the separation performances, the membrane was first mounted in a permeation cell (permeation area $=1.77 \mathrm{~cm}^{2}$ ). The up and downstream of the membrane were subjected to test gas $\left(\mathrm{C}_{2} \mathrm{H}_{4} / \mathrm{C}_{2} \mathrm{H}_{6}\right.$ mixture) and inert carrier gas (i.e., $\left.\mathrm{He}\right)$, which flow rate is set as $20 \mathrm{sccm}$ and $5 \mathrm{sccm}$, respectively. Mass flow controllers were used to control the flow rate. At periodic time interval, gases that permeated through the membrane were sampled by a gas chromatography fitted with a thermal conductivity detector (TCD), using He as a sweeping gas. The steady-state reading was taken after the concentrations of $\mathrm{C}_{2} \mathrm{H}_{4}$ and $\mathrm{C}_{2} \mathrm{H}_{6}$ does not demonstrate substantial fluctuation. During the measurement, the environment was remained isothermal $\left(35^{\circ} \mathrm{C}\right)$. At least three different samples for each membrane type were measured to ensure that the gas permeation results are reproducible, with the error bars determined by standard deviation. 


\subsection{4. $\mathrm{C}_{2} \mathrm{H}_{4}$ and $\mathrm{C}_{2} \mathrm{H}_{6}$ Adsorption Analysis of Membranes}

Similarly, pure component $\mathrm{C}_{2} \mathrm{H}_{4}$ and $\mathrm{C}_{2} \mathrm{H}_{6}$ adsorption of each respective membrane was evaluated using the conditions as elaborated in Section 2.6.1 to give the solubility-diffusivity behavior of the membranes. The same activation conditions as described above were used for all membranes. All the isotherms were fitted using single-site Langmuir equation (equation 2) so as to determine the $\mathrm{C}_{2} \mathrm{H}_{4}$ and $\mathrm{C}_{2} \mathrm{H}_{6}$ adsorption at a specified pressure. The results of all parameters were summarized in Table S1. The solubility, $S$, of $\mathrm{C}_{2} \mathrm{H}_{4}$ and $\mathrm{C}_{2} \mathrm{H}_{6}$ in each membrane can be determined using Equation (5):

$$
S=\frac{q \rho}{p}
$$

where $q=$ amount of gas adsorbed per unit membrane mass based on a specified pressure, $p$, and $\rho=$ membrane's density. The gas diffusivity, $D$, was calculated by taking the ratio between permeability, $P$ and solubility, $S$, given that $P=D S$. The units of $P$ and $S$ are expressed as $\mathrm{mol} \cdot \mathrm{m} / \mathrm{m}^{2} \cdot \mathrm{s} \cdot$ bar and $\mathrm{mol} / \mathrm{m}^{3} \cdot$ bar, respectively.

\section{Results and Discussion}

\subsection{Characterization of Nanocrystal HKUST-1}

XRD (X-ray diffraction) as shown in Figure S1a was first verified to confirm the crystallinity of nanocrystal HKUST-1. The diffraction peaks are in general similar to the data reported in the literature [34,63], as well as the simulated pattern of HKUST-1 [64]. $\mathrm{N}_{2}$ physisorption measurement at $-196{ }^{\circ} \mathrm{C}(77 \mathrm{~K})$ (Figure $\mathrm{S} 1 \mathrm{~b}$ ) showed a large $\mathrm{N}_{2}$ sorption at low $\mathrm{P} / \mathrm{P}_{\mathrm{o}}$, which is a clear indication of a Type 1 isotherm. In other words, large micropore volumes are present in our nanocrystal HKUST-1 sample (Table S2). The FT-IR analysis indicates a successful formation of the characteristic $\mathrm{Cu}_{2}(\mathrm{COO})_{4}$ paddle wheel of HKUST-1, on the basis of the absorption bands detected at 1647, 1615, 1451 and $1376 \mathrm{~cm}^{-1}$ (Figure S1c) [65]. Besides, the nanocrystal HKUST-1 is thermally stable up until $350{ }^{\circ} \mathrm{C}$, as shown by the TGA curve (Figure S1d). Successful nanosizing of HKUST-1 crystals was demonstrated through the FESEM image (Figure 3a). As exemplified by the particle size distribution (Figure 3b), the mean particle size is about $260 \mathrm{~nm}$ with a distribution ranging from 100-500 nm, which is a stark contrast to the micron-sized Basolite C300 HKUST-1 bulk crystals [66].
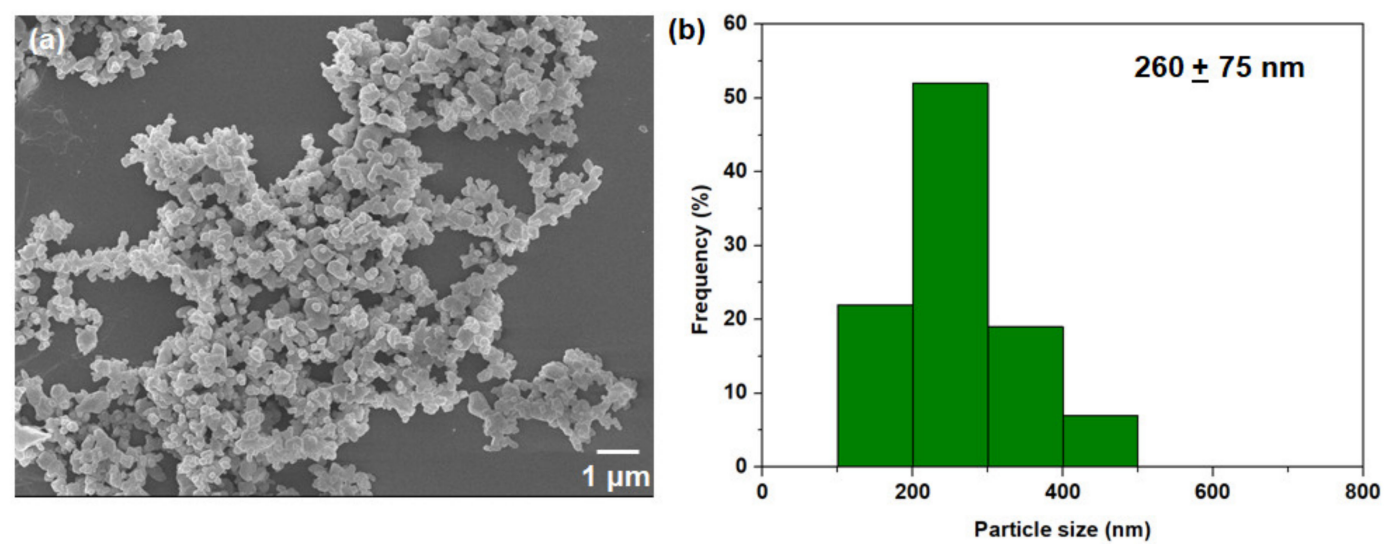

Figure 3. (a) FESEM image of nanocrystal HKUST-1; (b) Particle size distribution of nanocrystal HKUST-1. The mean and standard deviation are included in the figure.

\section{2. $\mathrm{C}_{2} \mathrm{H}_{4}$ and $\mathrm{C}_{2} \mathrm{H}_{6}$ Adsorption of Nanocrystal HKUST-1}

To attest the merits of using nanocrystal HKUST-1, the $\mathrm{C}_{2} \mathrm{H}_{4}$ and $\mathrm{C}_{2} \mathrm{H}_{6}$ adsorption isotherms were studied at $35{ }^{\circ} \mathrm{C}$ (Figure $4 \mathrm{a}$ ). The $\mathrm{C}_{2} \mathrm{H}_{4}$ and $\mathrm{C}_{2} \mathrm{H}_{6}$ isotherm at $25^{\circ} \mathrm{C}$ were also included in Figure S2a,b (fitting parameters are summarized in Table S3) and the results were used in the calculation of the 
isosteric heat of adsorption $\left(-Q_{s t}\right)$. Generally, nanocrystal HKUST-1 showed a preferential adsorption towards $\mathrm{C}_{2} \mathrm{H}_{4}$ and $\mathrm{C}_{2} \mathrm{H}_{6}$ despite the latter having a higher polarizability $\left(\mathrm{C}_{2} \mathrm{H}_{4}: 42.5 \times 10^{-25} \mathrm{~cm}^{3}\right.$ vs. $\mathrm{C}_{2} \mathrm{H}_{6}: 44.3 \times 10^{-25} \mathrm{~cm}^{3}$ ) [67]. We attribute this observation to the presence of coordinatively unsaturated metal sites that allows the formation of olefin $\left(\mathrm{C}_{2} \mathrm{H}_{4}\right)$ complexation. Metal sites are generally capable of accepting $\pi$ electron from the olefin as well as donating electrons to the empty $\pi^{*}$ antibonding orbital of the olefin, thus leading to a stronger $\mathrm{C}_{2} \mathrm{H}_{4}$ interaction by the metal cations, which in this case is $\mathrm{Cu}^{2+}[68,69]$. This is further verified by a higher $-Q_{s t}$ at zero coverage for $\mathrm{C}_{2} \mathrm{H}_{4}$ (36.3 $\left.\mathrm{kJ} \mathrm{mol}^{-1}\right)$ as compared to $\mathrm{C}_{2} \mathrm{H}_{6}\left(27.9 \mathrm{~kJ} \mathrm{~mol}^{-1}\right)$ (Figure S2c), indicating that the adsorption of olefin to the unsaturated metal sites is indeed favorable. The overall IAST selectivity as a function of the feed pressure was plotted in Figure $4 \mathrm{~b}$, where the $\mathrm{C}_{2} \mathrm{H}_{4} / \mathrm{C}_{2} \mathrm{H}_{6}$ selectivity is approximately at 3.7 under 1 bar feed pressure.
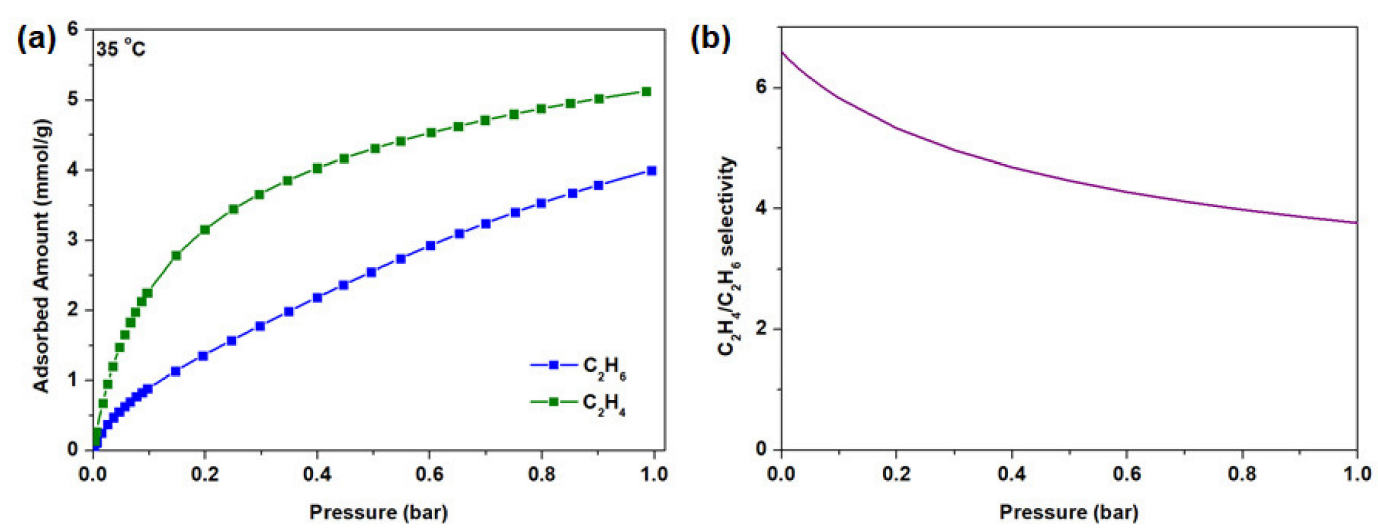

Figure 4. (a) $\mathrm{C}_{2} \mathrm{H}_{4}$ and $\mathrm{C}_{2} \mathrm{H}_{6}$ adsorption isotherm of nanocrystal HKUST-1 at $35{ }^{\circ} \mathrm{C}$; (b) The Ideal Adsorbed Solution Theory (IAST) selectivity of HKUST-1 nanocrystal at $35{ }^{\circ} \mathrm{C}$ as a function of feed pressure.

\subsection{Characterizaiton of Mixed-Matrix Membranes}

In this work, in-house polyimide ODPA-TMPDA and 6FDA-TMPDA polymers were used for mixed-matrix membrane fabrication. To ensure successful syntheses of the polyimides, FT-IR spectroscopy was conducted to verify the functional groups (Figure S3). In general, both polymers showed the characteristic imide peaks at $1774 \mathrm{~cm}^{-1}$ and $1719 \mathrm{~cm}^{-1}$ that corresponded to asymmetric and symmetric $\mathrm{C}=\mathrm{O}$ stretching, respectively. Besides, $\mathrm{C}-\mathrm{N}$ stretching $\left(1358 \mathrm{~cm}^{-1}\right)$ was also detected in both spectra $[39,70,71]$. As the polyimides were synthesized via a two-step reaction (where monomers were first condensed to form polyamic acid before subsequent chemical imidization), it is important to determine that all polyamic acid has been successfully reacted. This is evidenced by the absence of the $\mathrm{O}-\mathrm{H}$ peak $\left(3500 \mathrm{~cm}^{-1}\right)$, which indicates a successful imidization process (Figure S3). The resulting polymer is well-dissolved in chloroform, which is a typical solvent used in polymeric membrane fabrication. Hence, mixed-matrix membranes were developed from these polyimides using 10 and $20 \mathrm{wt} \%$ loadings of HKUST-1. Typically, a $20 \mathrm{wt} \%$ filler loading is not uncommon for a three-dimensional porous filler in a mixed-matrix membrane [19]. In this work, the $20 \mathrm{wt} \%$ loading of HKUST-1 is the optimal amount, as also evidenced by other studies on mixed-matrix membranes [72,73]. Next, the structural morphology of the membranes was examined using FESEM (Figure 5). In general, the cross-sectional morphology of all membranes exhibits an intact and homogeneous integrity. The polymer/filler interface is visibly free from the sieve-in-a-cage morphology-a defective interface that is commonly found in zeolite-based mixed-matrix membranes [74]. This good structural integrity stems from the organic moieties of the nanocrystal HKUST-1, which increases the compatibility between the filler and polymer. The nanosized HKUST-1 crystals can also facilitate easy wrapping by the polyimide chains, and coupled with the intrinsically good compatibility, a more intimate contact at the polymer/filler interface can be realized, rendering a defect-free mixed-matrix membrane $[50,66]$. 
Furthermore, as compared with micron-sized bulk HKUST-1 crystals, our nanosized HKUST-1 are less prone to particle sedimentation during membrane fabrication. This helps create a uniform filler dispersion as well as homogenous mixed-matrix membrane morphology, as evidenced by our FESEM images (Figure 5). In contrast, as observed by several other studies, micron-sized fillers are more likely to settle at the bottom of the membrane, creating potential defects in the membrane structure $[19,75]$. Additionally, TGA analysis revealed that the thermal stability of the polymers remained unchanged with the incorporation of nanocrystal HKUST-1 in the mixed-matrix membranes (Figure S4). Based on the profile, it can be observed that there are two peaks in the case of mixed-matrix membrane as compared with the one peak in pure polymeric membrane. The first peak corresponds to the degradation of the HKUST-1 nanocrystals in the membrane, as corroborated by the thermal stability profile of the nanocrystal HKUST-1 (Figure S1d). The second peak is attributed to the degradation of the polymer matrices. In terms of the mechanical properties of the mixed-matrix membranes, we are expecting a marginal decrease in comparison to the pure polymeric membranes due to the incorporation of the nanocrystal HKUST-1. However, this anticipated drop is unlikely to create a negative impact as the membranes continued to demonstrate good manageability and robustness during measurements and characterization. As reported by Ge and coworkers, the problem only surfaced at $50 \mathrm{wt} \%$ HKUST-1 loading when the mechanical properties of the membranes were reportedly found to be insufficient to support normal performance measurements [76].
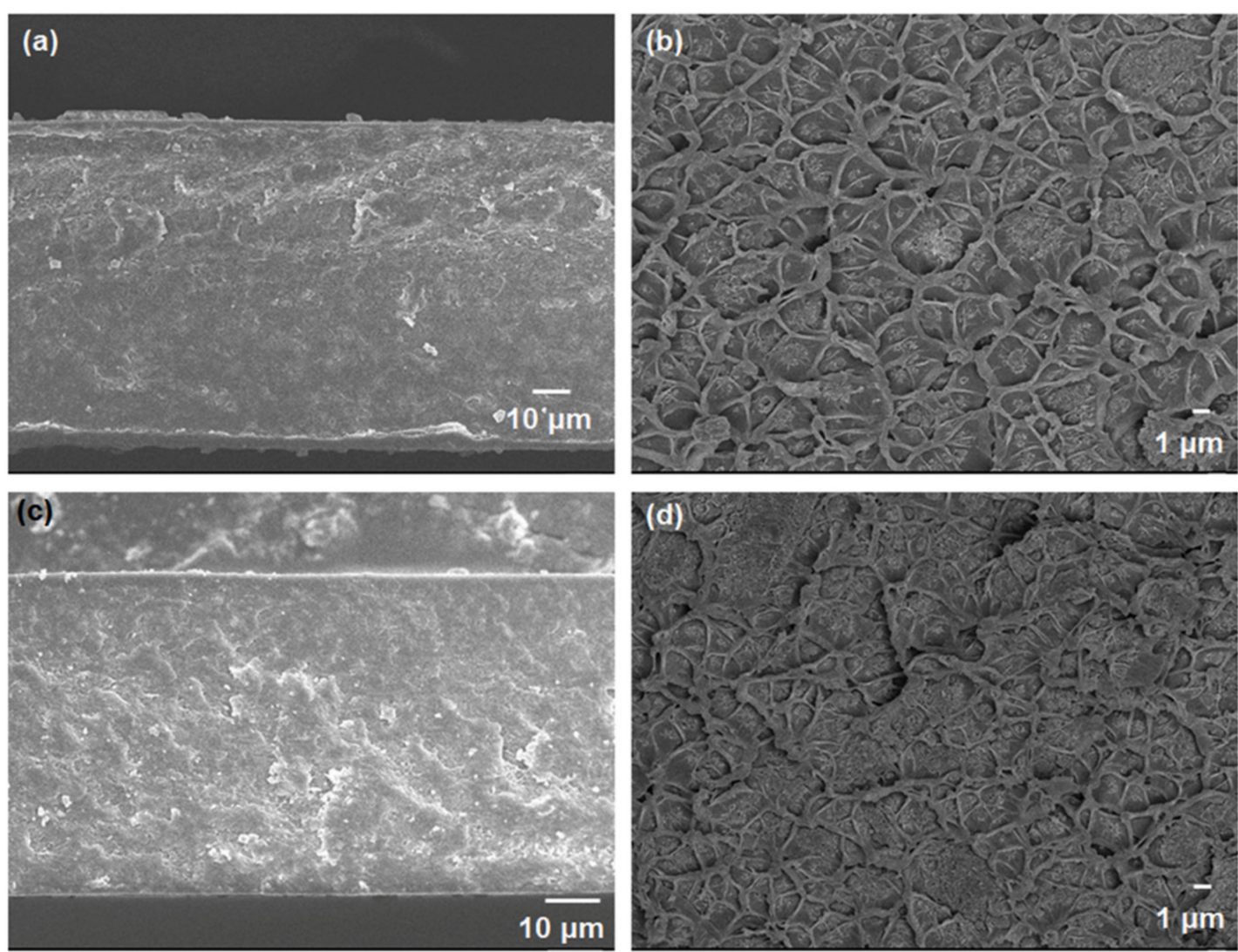

Figure 5. Cont. 

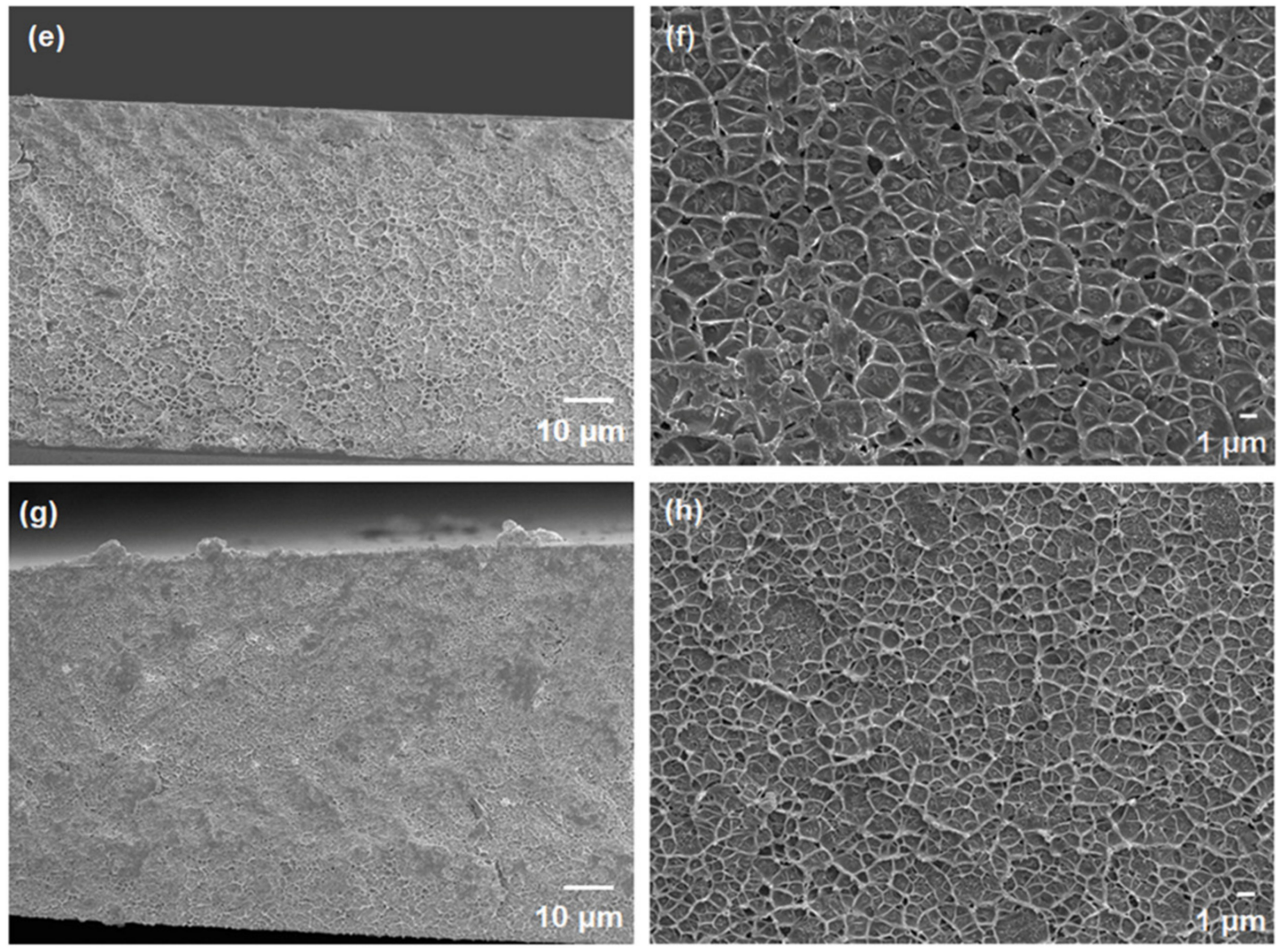

Figure 5. FESEM images of the mixed-matrix membranes: (a,b) $10 \mathrm{wt} \%$, and (c,d) $20 \mathrm{wt} \%$ HKUST-1 with ODPA-TMPDA; and (e,f) $10 \mathrm{wt} \%$, and $(\mathbf{g}, \mathbf{h}) 20 \mathrm{wt} \%$ HKUST-1 with 6FDA-TMPDA.

\subsection{Gas Permeation Behavior of Membranes}

Gas permeation analysis of each membrane was performed at $35{ }^{\circ} \mathrm{C}$ under 1 bar upstream pressure using ethylene/ethane $\left(\mathrm{C}_{2} \mathrm{H}_{4} / \mathrm{C}_{2} \mathrm{H}_{6}\right)$ gas at 50/50 mixture, with results summarized in Table 1 . In general, a substantial enhancement in the $\mathrm{C}_{2} \mathrm{H}_{4}$ permeability was observed when HKUST- 1 was loaded. Particularly, the incorporation of $20 \mathrm{wt} \%$ HKUST-1 gave a $155 \%$ and $69 \%$ improvement in $\mathrm{C}_{2} \mathrm{H}_{4}$ permeability when ODPA-TMPDA and 6FDA-TMPDA was used as the matrix, respectively. The improvement in permeability was, however, accompanied by a marginal drop in the $\mathrm{C}_{2} \mathrm{H}_{4} / \mathrm{C}_{2} \mathrm{H}_{6}$ selectivity. We reckon that the large pore window in the nanocrystal HKUST-1 reduces the transport resistance and allows faster diffusion, but it was not selective. Next, to attest our claims, we quantify the $\mathrm{C}_{2} \mathrm{H}_{4}$ and $\mathrm{C}_{2} \mathrm{H}_{6}$ diffusivity and solubility of these membranes (Figure 6). The calculated $\mathrm{C}_{2} \mathrm{H}_{4}$ and $\mathrm{C}_{2} \mathrm{H}_{6}$ diffusivity and solubility are compiled accordingly (Table 2). Based on the isotherm profile, substantially higher $\mathrm{C}_{2} \mathrm{H}_{4}$ and $\mathrm{C}_{2} \mathrm{H}_{6}$ adsorptions were observed for the mixed-matrix membranes as compared to pure polymeric membranes. This increases both the absolute values of the $\mathrm{C}_{2} \mathrm{H}_{4}$ and $\mathrm{C}_{2} \mathrm{H}_{6}$ diffusivity and solubility of the mixed-matrix membranes. Nevertheless, the solubility selectivity remains relatively constant while the diffusivity selectivity decreases slightly. Evidently, our results suggest that the incorporation of nanocrystal HKUST-1 indeed provides diffusion pathways of lower resistance to facilitate gas transport, but these pathways are indiscriminatory towards $\mathrm{C}_{2} \mathrm{H}_{4}$ and $\mathrm{C}_{2} \mathrm{H}_{6}$. The selectivity continues to be delivered by the polyimide matrices. 
Table 1. $\mathrm{C}_{2} \mathrm{H}_{4} / \mathrm{C}_{2} \mathrm{H}_{6}$ permeation behavior of pure ODPA-TMPDA and 6FDA-TMPDA membranes together with nanocrystal HKUST-1-containing mixed-matrix membranes. ${ }^{\text {a }}$

\begin{tabular}{ccc}
\hline Membrane & $\mathbf{C}_{2} \mathbf{H}_{4}$ Permeability (Barrer) & $\mathbf{C}_{2} \mathbf{H}_{4} / \mathbf{C}_{2} \mathbf{H}_{6}$ Selectivity \\
\hline ODPA-TMPDA & $6.3 \pm 0.4$ & $3.9 \pm 0.4$ \\
ODPA-TMPDA + 10 wt $\%$ HKUST-1 & $13.6 \pm 1.7$ & $3.6 \pm 0.3$ \\
ODPA-TMPDA + 20 wt $\%$ HKUST-1 & $16.0 \pm 0.2$ & $3.4 \pm 0.2$ \\
6FDA-TMPDA & $108 \pm 7.2$ & $2.5 \pm 0.1$ \\
6FDA-TMPDA + 10 wt $\%$ HKUST-1 & $148 \pm 11.8$ & $2.5 \pm 0.5$ \\
6FDA-TMPDA + 20 wt $\%$ HKUST-1 & $183 \pm 3.8$ & $2.4 \pm 0.1$ \\
\hline
\end{tabular}

a The measurement condition is stated as follows: 1 bar feed pressure and $\mathrm{C}_{2} \mathrm{H}_{4} / \mathrm{C}_{2} \mathrm{H}_{6}$ mixture (50/50) at $35^{\circ} \mathrm{C}$.
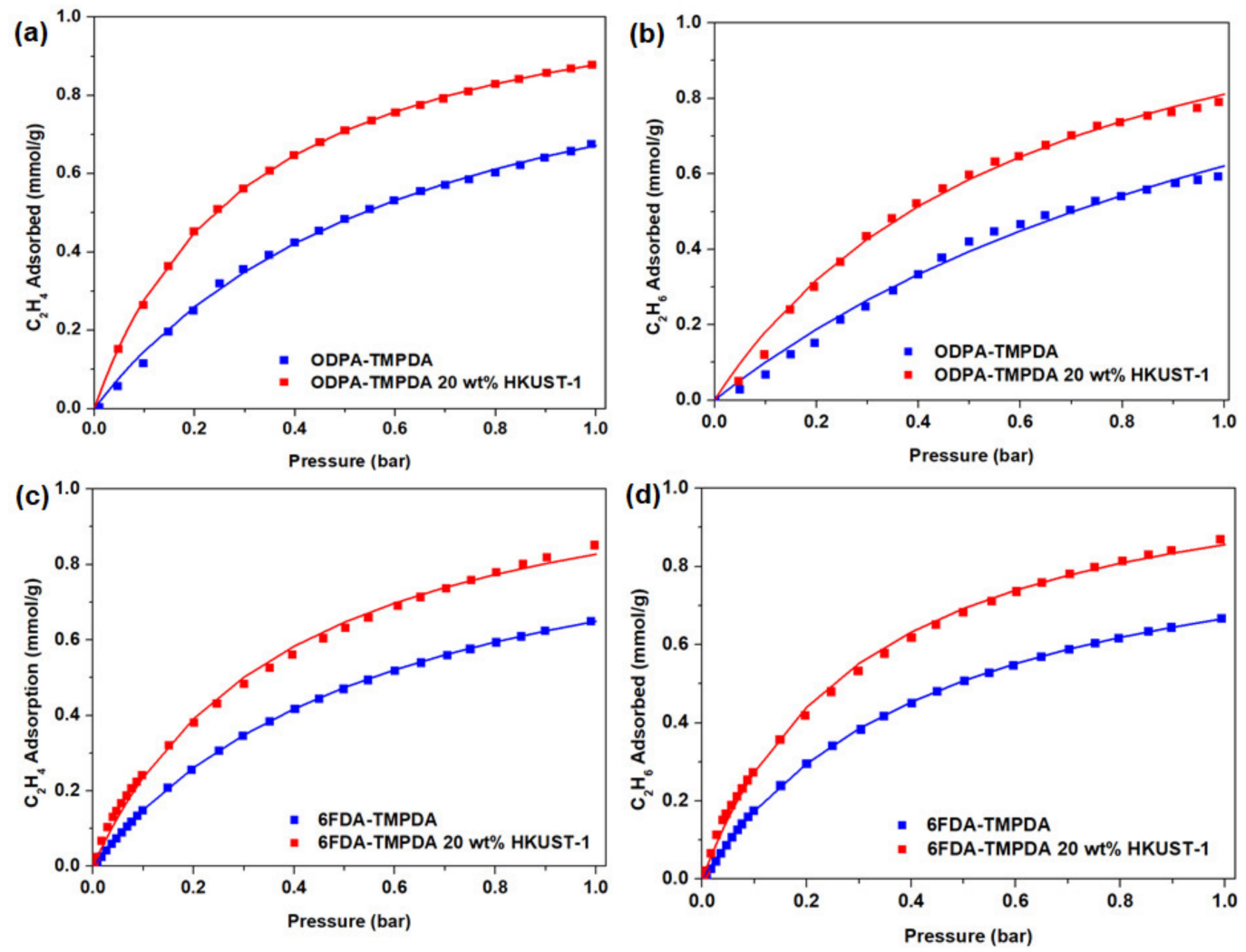

Figure 6. Adsorption isotherm of $(\mathbf{a}, \mathbf{c}) \mathrm{C}_{2} \mathrm{H}_{4}$ and $(\mathbf{b}, \mathbf{d}) \mathrm{C}_{2} \mathrm{H}_{6}$ of pure polymeric and mixed-matrix membranes.

Table 2. $\mathrm{C}_{2} \mathrm{H}_{4}$ and $\mathrm{C}_{2} \mathrm{H}_{6}$ solubility and diffusivity parameters of pure polymeric and mixed-matrix membranes at $35^{\circ} \mathrm{C}$.

\begin{tabular}{|c|c|c|c|c|c|c|c|}
\hline Membrane & $\begin{array}{l}\text { Density } \\
\left(\mathrm{g} \mathrm{cm}^{-3}\right)\end{array}$ & $\begin{array}{c}\mathrm{C}_{2} \mathrm{H}_{4} \\
\text { Solubility, } \times \\
10^{3}\left(\mathrm{~mol} \mathrm{~m}^{-3}\right. \\
\left.\text { bar }^{-1}\right)\end{array}$ & $\begin{array}{c}\mathrm{C}_{2} \mathrm{H}_{4} \\
\text { Diffusivity, } \\
\times 10^{-13} \\
\left(\mathrm{~m}^{2} \mathrm{~s}^{-1}\right)\end{array}$ & $\begin{array}{c}\mathrm{C}_{2} \mathrm{H}_{6} \\
\text { Solubility, } \times \\
10^{3}\left(\mathrm{~mol} \mathrm{~m}^{-3}\right. \\
\left.\text { bar }^{-1}\right)\end{array}$ & $\begin{array}{c}\mathrm{C}_{2} \mathrm{H}_{6} \\
\text { Diffusivity, } \\
\times 10^{-13} \\
\left(\mathrm{~m}^{2} \mathrm{~s}^{-1}\right)\end{array}$ & $\begin{array}{l}\text { Solubility } \\
\text { Selectivity }\end{array}$ & $\begin{array}{l}\text { Diffusivity } \\
\text { Selectivity }\end{array}$ \\
\hline $\begin{array}{l}\text { ODPA-TMPDA } \\
\text { ODPA-TMPDA }\end{array}$ & 1.25 & 1.21 & 0.394 & 0.989 & 0.124 & 1.22 & 3.17 \\
\hline $\begin{array}{l}+20 w \mathrm{t} \% \\
\text { HKUST-1 }\end{array}$ & 1.24 & 1.77 & 0.688 & 1.46 & 0.244 & 1.21 & 2.82 \\
\hline $\begin{array}{l}\text { 6FDA-TMPDA } \\
\text { 6FDA-TMPDA }\end{array}$ & 1.26 & 1.19 & 0.687 & 1.28 & 2.57 & 0.933 & 2.68 \\
\hline $\begin{array}{l}+20 w t \% \\
\text { HKUST-1 }\end{array}$ & 1.22 & 1.58 & 0.880 & 1.69 & 3.50 & 0.934 & 2.51 \\
\hline
\end{tabular}




\subsection{Comparison of Gas Separation Performance}

Subsequently, our mixed-matrix membranes were benchmarked against an upper bound for the $\mathrm{C}_{2} \mathrm{H}_{4} / \mathrm{C}_{2} \mathrm{H}_{6}$ gas separation performance. Besides, the membrane performances were compared to the current literature data. As demonstrated in Figure 7a, the performances of our mixed-matrix membranes edge generally close to the upper bound limit as compared to the pure polymeric membranes. The choice of polymer matrix is an important parameter that can critically affect the overall performance of the mixed-matrix membranes. This deduction is corroborated as we compare the performance of our mixed-matrix membranes with the current literature data. Furthermore, most studies to date mainly focus on pure gas permeation (Table 3), giving only ideal $\mathrm{C}_{2} \mathrm{H}_{4} / \mathrm{C}_{2} \mathrm{H}_{6}$ selectivity. While evaluating ideal selectivity is a convenient way to assess membrane performance, it is not entirely representative as we know that competitive sorption by two gases of similar polarizabilities and dipole moments can result in lower than expected performance, rendering most results in the literature overrated. Thus, to indicate the potential relevance in industrial gas separation process, the investigation of gas permeation under mixture-gas is always desirable as mixture-gas evaluation generally gives more accurate gas separation performances. Comparing mixture-gas performances with others in the literature [52,60], our mixed-matrix membranes are highly competitive, as shown in Figure $7 \mathrm{~b}$. There are some high-performing mixed-matrix membranes, comprising advanced MOFs (MOF-74) [60], which exhibit separation performances that transcend the upper bound limit (Figure 7b). From a practical perspective, such tailor-made MOFs are not readily scalable and have a lower potential for commercialization. In contrast, commercial HKUST-1 (Basolite C300) is already available in the market, and hence up-scaling nanocrystal HKUST-1 is deemed less challenging. On this basis, we believe that leveraging nanocrystal HKUST-1 as a filler for mixed-matrix membranes for $\mathrm{C}_{2} \mathrm{H}_{4} / \mathrm{C}_{2} \mathrm{H}_{6}$ separation is not only effective but also attractive.
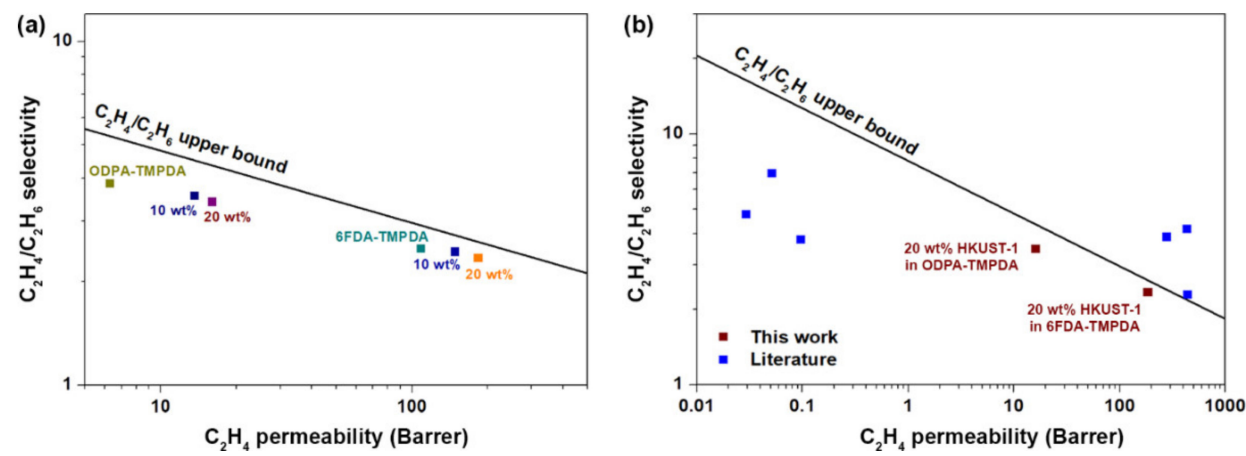

Figure 7. (a) Comparison of the synthesized membranes (pure polymer and mixed-matrix) with reference to the $\mathrm{C}_{2} \mathrm{H}_{4} / \mathrm{C}_{2} \mathrm{H}_{6}$ upper bound. The upper bound is constructed based on ref. [24]. (b) Mixture-gas performance comparison of our mixed-matrix membranes with literature data [52,60].

Table 3. Summary of $\mathrm{C}_{2} \mathrm{H}_{4} / \mathrm{C}_{2} \mathrm{H}_{6}$ pure component gas permeation results of the mixed-matrix membranes that are available in the literature. ${ }^{\text {a }}$

\begin{tabular}{|c|c|c|c|c|c|c|c|c|c|}
\hline \multirow{3}{*}{ Filler } & \multirow{3}{*}{ Polymer } & \multirow{3}{*}{$\begin{array}{c}\text { Filler } \\
\text { Loading } \\
\text { (wt } \%)\end{array}$} & \multicolumn{6}{|c|}{ Separation Performance } & \multirow{3}{*}{ Ref. } \\
\hline & & & \multicolumn{2}{|c|}{ Testing Condition } & \multirow{2}{*}{$\begin{array}{c}P\left(\mathrm{C}_{2} \mathrm{H}_{4}\right) \\
\text { (Barrer) }\end{array}$} & \multirow{2}{*}{$\begin{array}{c}\text { Permeability } \\
\text { Enhancement } \\
(\%)\end{array}$} & \multirow[b]{2}{*}{$\alpha\left(\mathrm{C}_{2} \mathrm{H}_{4} / \mathrm{C}_{2} \mathrm{H}_{6}\right)$} & \multirow{2}{*}{$\begin{array}{c}\text { Selectivity } \\
\text { Enhancement } \\
(\%)\end{array}$} & \\
\hline & & & $\begin{array}{l}\text { Pressure } \\
\text { (bar) }\end{array}$ & $\begin{array}{l}\text { Temp. } \\
\left({ }^{\circ} \mathrm{C}\right)\end{array}$ & & & & & \\
\hline Silica nanoparticles & CA & 30 & 2 & 35 & 0.11 & 100 & 4.1 & 173 & [5] \\
\hline Silica nanoparticles & Matrimid $^{\circledR}$ & 20 & 3 & 30 & 0.19 & 137.5 & 3.2 & 98.1 & [51] \\
\hline ZIF-8 & 6FDA-DAM & 23.8 & 2 & 35 & 72.9 & 85.0 & 3.2 & -3.1 & [77] \\
\hline ZIF-8 & DBzPBI-BuI & 30 & 2.7 & 35 & 111 & 2953 & 2.6 & -2.29 & [13] \\
\hline HKUST-1 b & ODPA-TMPDA & 20 & 1 & 35 & 16 & 155.2 & 3.4 & -11.6 & This work \\
\hline HKUST- 1 b & 6FDA-TMPDA & 20 & 1 & 35 & 183 & 69.4 & 2.4 & -6.0 & This work \\
\hline
\end{tabular}

${ }^{\text {a }}$ Optimal performance in terms of $\mathrm{C}_{2} \mathrm{H}_{4}$ permeability and (or) $\mathrm{C}_{2} \mathrm{H}_{4} / \mathrm{C}_{2} \mathrm{H}_{6}$ selectivity were selected and tabulated in this table; ${ }^{b}$ The data for this work is included as reference. 


\section{Conclusions}

Nanocrystal HKUST-1 was successfully synthesized and incorporated as mixed-matrix membranes in both ODPA-TMPDA and 6FDA-TMPDA matrices. Nanosizing HKUST-1 not only helps to mitigate polymer/filler interfacial defects, but also achieves a homogeneous morphology of the mixed-matrix membranes. The coordinatively unsaturated open metal sites of the nanocrystal HKUST-1 favor $\mathrm{C}_{2} \mathrm{H}_{4}$ adsorption. At $20 \mathrm{wt} \%$ nanocrystal HKUST-1 loading, the $\mathrm{C}_{2} \mathrm{H}_{4}$ permeability was found to increase up to $155 \%$ with a marginal drop in the $\mathrm{C}_{2} \mathrm{H}_{4} / \mathrm{C}_{2} \mathrm{H}_{6}$ selectivity. We attribute this to the large pore size of HKUST-1 $(9 \times 9 \AA)$, which provides indiscriminatory diffusion pathways of lower resistance to the gas molecules. Solubility-diffusivity analysis of both $\mathrm{C}_{2} \mathrm{H}_{4}$ and $\mathrm{C}_{2} \mathrm{H}_{6}$ gases corroborated this conclusion. In addition, it was revealed that the polymer matrices continued to deliver the required $\mathrm{C}_{2} \mathrm{H}_{4} / \mathrm{C}_{2} \mathrm{H}_{6}$ selectivity as demonstrated by the relatively constant solubility selectivity in the mixed-matrix membranes. As a result, the performance of our mixed-matrix membranes was found to edge closer towards the upper bound, enabling nanocrystal HKUST-1 as an effective porous filler to enhance the performance of mixed-matrix membranes for ethylene/ethane separation.

Supplementary Materials: The following are available online at http://www.mdpi.com/2077-0375/10/4/74/s1, Figure S1: Characterization of nanocrystal HKUST-1, showing (a) X-ray diffraction pattern, (b) $\mathrm{N}_{2}$ physisorption isotherm at $77 \mathrm{~K}$ (open and closed symbols indicate adsorption and desorption branches, respectively), (c) FT-IR spectrum, as well as (d) TGA curve, showing weight loss and $d m / d T$ against temperature, of nanocrystal HKUST-1 from 40 to $800{ }^{\circ} \mathrm{C}$. Figure S2: $\mathrm{C}_{2} \mathrm{H}_{4}$ and $\mathrm{C}_{2} \mathrm{H}_{6}$ adsorption of HKUST-1 at (a) $25{ }^{\circ} \mathrm{C}$ and (b) $35{ }^{\circ} \mathrm{C}$, (c) $-Q_{\text {st }}$ of HKUST-1 for $\mathrm{C}_{2} \mathrm{H}_{4}$ and $\mathrm{C}_{2} \mathrm{H}_{6}$. Figure S3: FT-IR spectrum of (a) ODPA-TMPDA and (b) 6FDA-TMPDA polymer. Figure S4: TGA analysis $(\mathrm{a}, \mathrm{b})$ weight loss against temperature and $(\mathrm{c}, \mathrm{d}) d \mathrm{~m} / d \mathrm{~T}$ against temperature of $10 \mathrm{wt} \%$ and $20 \mathrm{wt} \%$ nanocrystal HKUST-1 in $(\mathrm{a}, \mathrm{c})$ ODPA-TMPDA and $(\mathrm{b}, \mathrm{d})$ 6FDA-TMPDA polymer. Table S1: Fitting parameters for $\mathrm{C}_{2} \mathrm{H}_{4}$ and $\mathrm{C}_{2} \mathrm{H}_{6}$ for membranes at $35^{\circ} \mathrm{C}$. Table S2: Porosity properties of nanocrystal HKUST- 1 based on $\mathrm{N}_{2}$ physisorption at $77 \mathrm{~K}$. Table S3: Fitting parameters for $\mathrm{C}_{2} \mathrm{H}_{4}$ and $\mathrm{C}_{2} \mathrm{H}_{6}$ for HKUST- 1 at 25 and $35^{\circ} \mathrm{C}$.

Author Contributions: Original draft preparation and experimental: C.Y.C., assistance in the synthesis of polymer: S.A.S.C.S. and W.L.; Writing-review and editing: K.G. and T.-H.B. All authors have read and agreed to the published version of this manuscript.

Funding: T.-H.B. would like to thank Korea Advanced Institute of Science and Technology (KAIST) for the financial support. K.G would also like to thank the Singapore Economic Development Board (EDB) for the funding support to Singapore Membrane Technology Centre (SMTC).

Conflicts of Interest: The authors declare no conflict of interest.

\section{Nomenclature}

List of symbols

$b_{1}, b_{2}$

$d m / d T$

$D$

$p$

$P$

$-Q_{s t}$

$q$

$q_{\text {sat }, 1}, q_{s a t, 2}$

$R$

$S$

$T$

$x_{1}, x_{2}$

$y_{1}, y_{2}$

$\rho$
Langmuir constant $\left(\right.$ bar $\left.^{-1}\right)$

Change in mass per unit temperature $\left(m g^{o} \mathrm{C}^{-1}\right)$

Diffusivity $\left(\mathrm{m}^{2} / \mathrm{s}\right)$

Pressure (bar)

Permeability (Barrer or $\mathrm{mol} \cdot \mathrm{m} / \mathrm{m}^{2} \cdot \mathrm{s} \cdot \mathrm{bar}$ )

Isosteric heat of adsorption $\left(\mathrm{kJ} \mathrm{mol}^{-1}\right)$

Adsorbed amount ( $\mathrm{mmol} \mathrm{g}^{-1}$ )

Saturation loading $\left(\mathrm{mmol} \mathrm{g}^{-1}\right)$

Molar gas constant $\left(\mathrm{J} \mathrm{mol}^{-1} \mathrm{~K}^{-1}\right)$

Solubility $\left(\mathrm{mol} / \mathrm{m}^{3} \cdot\right.$ bar $)$

Temperature $(K)$

Mole fractions of the adsorbed phase

Mole fractions of the gas phase

Density $\left(\mathrm{g} \mathrm{cm}^{-3}\right)$ 


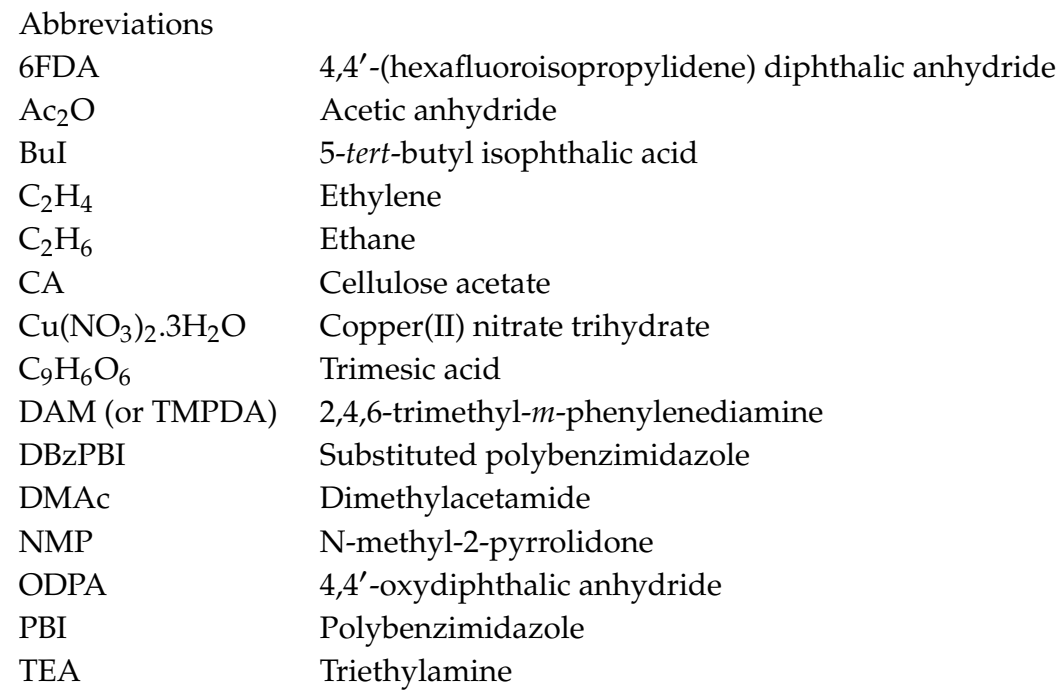

\section{References}

1. Sholl, D.; Lively, R. Seven chemical separations to change the world. Nature 2016, 532, 435-437. [CrossRef]

2. Cetinkaya, E.; Liu, N.; Jan Simons, T.; Wallach, J. Petrochemicals 2030: Reinventing the Way to Win in a Changing Industry. Available online: https:/www.mckinsey.com/industries/chemicals/our-insights/ petrochemicals-2030-reinventing-the-way-to-win-in-a-changing-industry\# (accessed on 8 April 2020).

3. Hays, K.; Cambeiro, M.; Dobashi, F.; Ang, S. New Capacities, Weaker Downstream Markets to Weigh on Ethylene in 2020. Available online: https://www.spglobal.com/platts/en/market-insights/latest-news/ petrochemicals/112619-commodities-2020-new-capacities-weaker-downstream-markets-to-weigh-onethylene (accessed on 4 April 2020).

4. Wang, X.; Wu, Y.; Zhou, X.; Xiao, J.; Xia, Q.; Wang, H.; Li, Z. Novel C-PDA adsorbents with high uptake and preferential adsorption of ethane over ethylene. Chem. Eng. Sci. 2016, 155, 338-347. [CrossRef]

5. Naghsh, M.; Sadeghi, M.; Moheb, A.; Chenar, M.P.; Mohagheghian, M. Separation of ethylene/ethane and propylene/propane by cellulose acetate-silica nanocomposite membranes. J. Membr. Sci. 2012, 423, 97-106. [CrossRef]

6. Lee, J.; Chuah, C.Y.; Kim, J.; Kim, Y.; Ko, N.; Seo, Y.; Kim, K.; Bae, T.H.; Lee, E. Separation of Acetylene from Carbon Dioxide and Ethylene by a Water-Stable Microporous Metal-Organic Framework with Aligned Imidazolium Groups inside the Channels. Angew. Chem. Int. Ed. 2018, 57, 7869-7873. [CrossRef] [PubMed]

7. Nitzsche, R.; Budzinski, M.; Gröngröft, A. Techno-economic assessment of a wood-based biorefinery concept for the production of polymer-grade ethylene, organosolv lignin and fuel. Bioresour. Technol. 2016, 200, 928-939. [CrossRef]

8. Santos-Panqueva, Y.; Guerrero-Fajardo, C.A.; Cuevas-Rodriguez, E.O.; Picos-Corrales, L.A.; Silva, C.M.; Contreras-Andrade, I. Production of bio-ethylene from wastes of microalgae to biodiesel biorefinery. Waste Biomass Valoriz. 2019, 10, 377-386. [CrossRef]

9. De Jong, E.; Jungmeier, G. Chapter 1-Biorefinery Concepts in Comparison to Petrochemical Refineries. In Industrial Biorefineries \& White Biotechnology; Pandey, A., Höfer, R., Taherzadeh, M., Nampoothiri, K.M., Larroche, C., Eds.; Elsevier: Amsterdam, The Netherlands, 2015; pp. 3-33. [CrossRef]

10. Bennett, S.J.; Pearson, P.J.G. From petrochemical complexes to biorefineries? The past and prospective co-evolution of liquid fuels and chemicals production in the UK. Chem. Eng. Res. Des. 2009, 87, 1120-1139. [CrossRef]

11. Alfano, S.; Berruti, F.; Denis, N.; Santagostino, A. The Future of Second-Generation Biomass. Available online: https://www.mckinsey.com/business-functions/sustainability/our-insights/the-future-of-secondgeneration-biomass (accessed on 8 April 2020).

12. Liang, W.; Zhang, Y.; Wang, X.; Wu, Y.; Zhou, X.; Xiao, J.; Li, Y.; Wang, H.; Li, Z. Asphalt-derived high surface area activated porous carbons for the effective adsorption separation of ethane and ethylene. Chem. Eng. Sci. 2017, 162, 192-202. [CrossRef] 
13. Kunjattu, S.H.; Ashok, V.; Bhaskar, A.; Pandare, K.; Banerjee, R.; Kharul, U.K. ZIF-8@ DBzPBI-BuI composite membranes for olefin/paraffin separation. J. Membr. Sci. 2018, 549, 38-45. [CrossRef]

14. Van Miltenburg, A.; Zhu, W.; Kapteijn, F.; Moulijn, J. Adsorptive separation of light olefin/paraffin mixtures. Chem. Eng. Res. Des. 2006, 84, 350-354. [CrossRef]

15. Burns, R.L.; Koros, W.J. Defining the challenges for $\mathrm{C}_{3} \mathrm{H}_{6} / \mathrm{C}_{3} \mathrm{H}_{8}$ separation using polymeric membranes. J. Membr. Sci. 2003, 211, 299-309. [CrossRef]

16. Sungpet, A.; Way, J.; Thoen, P.; Dorgan, J. Reactive polymer membranes for ethylene/ethane separation. J. Membr. Sci. 1997, 136, 111-120. [CrossRef]

17. Staudt-Bickel, C.; Koros, W.J. Olefin/paraffin gas separations with 6FDA-based polyimide membranes. J. Membr. Sci. 2000, 170, 205-214. [CrossRef]

18. Wang, H.; Werth, S.; Schiestel, T.; Caro, J. Perovskite Hollow-Fiber Membranes for the Production of Oxygen-Enriched Air. Angew. Chem. Int. Ed. 2005, 44, 6906-6909. [CrossRef] [PubMed]

19. Gong, H.; Chuah, C.Y.; Yang, Y.; Bae, T.-H. High performance composite membranes comprising $\mathrm{Zn}(\text { pyrz })_{2}\left(\mathrm{SiF}_{6}\right)$ nanocrystals for $\mathrm{CO}_{2} / \mathrm{CH}_{4}$ separation. J. Ind. Eng. Chem. 2018, 60, 279-285. [CrossRef]

20. Chuah, C.Y.; Kim, K.; Lee, J.; Koh, D.-Y.; Bae, T.-H. $\mathrm{CO}_{2}$ absorption using membrane contactors: Recent progress and future perspective. Ind. Eng. Chem. Res. 2019. [CrossRef]

21. Jiang, X.; Kumar, A. Performance of silicone-coated polymeric membrane in separation of hydrocarbons and nitrogen mixtures. J. Membr. Sci. 2005, 254, 179-188. [CrossRef]

22. Pinnau, I.; Toy, L.G. Solid polymer electrolyte composite membranes for olefin/paraffin separation. J. Membr. Sci. 2001, 184, 39-48. [CrossRef]

23. Chuah, C.Y.; Goh, K.; Yang, Y.; Gong, H.; Li, W.; Karahan, H.E.; Guiver, M.D.; Wang, R.; Bae, T.-H. Harnessing filler materials for enhancing biogas separation membranes. Chem. Rev. 2018, 118, 8655-8769. [CrossRef]

24. Rungta, M.; Zhang, C.; Koros, W.J.; Xu, L. Membrane-based ethylene/ethane separation: The upper bound and beyond. AIChE J. 2013, 59, 3475-3489. [CrossRef]

25. Robeson, L.M. Correlation of separation factor versus permeability for polymeric membranes. J. Membr. Sci. 1991, 62, 165-185. [CrossRef]

26. Zhang, C.; Dai, Y.; Johnson, J.R.; Karvan, O.; Koros, W.J. High performance ZIF-8/6FDA-DAM mixed matrix membrane for propylene/propane separations. J. Membr. Sci. 2012, 389, 34-42. [CrossRef]

27. Robeson, L.M. The upper bound revisited. J. Membr. Sci. 2008, 320, 390-400. [CrossRef]

28. Yang, Y.; Chuah, C.Y.; Nie, L.; Bae, T.-H. Enhancing the mechanical strength and $\mathrm{CO}_{2} / \mathrm{CH}_{4}$ separation performance of polymeric membranes by incorporating amine-appended porous polymers. J. Membr. Sci. 2019, 569, 149-156. [CrossRef]

29. Yang, Y.; Goh, K.; Weerachanchai, P.; Bae, T.-H. 3D covalent organic framework for morphologically induced high-performance membranes with strong resistance toward physical aging. J. Membr. Sci. 2019, 574, $235-242$. [CrossRef]

30. Pera-Titus, M. Porous inorganic membranes for $\mathrm{CO}_{2}$ capture: Present and prospects. Chem. Rev. 2013, 114, 1413-1492. [CrossRef]

31. Usman, M.; Ahmed, A.; Yu, B.; Peng, Q.; Shen, Y.; Cong, H. A review of different synthetic approaches of amorphous intrinsic microporous polymers and their potential applications in membrane-based gases separation. Eur. Polym. J. 2019, 120, 109262. [CrossRef]

32. Álvarez, C.; Lozano, Á.E.; Juan-y-Seva, M.; de la Campa, J.G. Gas separation properties of aromatic polyimides with bulky groups. Comparison of experimental and simulated results. J. Membr. Sci. 2020, 602, 117959. [CrossRef]

33. Ploegmakers, J.; Japip, S.; Nijmeijer, K. Mixed matrix membranes containing MOFs for ethylene/ethane separation-Part B: Effect of $\mathrm{Cu}_{3} \mathrm{BTC}_{2}$ on membrane transport properties. J. Membr. Sci. 2013, 428, 331-340. [CrossRef]

34. Zamaro, J.M.; Pérez, N.C.; Miró, E.E.; Casado, C.; Seoane, B.; Téllez, C.; Coronas, J. HKUST-1 MOF: A matrix to synthesize $\mathrm{CuO}$ and $\mathrm{CuO}-\mathrm{CeO}_{2}$ nanoparticle catalysts for $\mathrm{CO}$ oxidation. Chem. Eng. J. 2012, 195, 180-187. [CrossRef]

35. Casado-Coterillo, C.; Fernández-Barquín, A.; Zornoza, B.; Téllez, C.; Coronas, J.; Irabien, Á. Synthesis and characterisation of $\mathrm{MOF} /$ ionic liquid/chitosan mixed matrix membranes for $\mathrm{CO}_{2} / \mathrm{N}_{2}$ separation. $R S C A d v$. 2015, 5, 102350-102361. [CrossRef] 
36. Pu, S.; Wang, J.; Li, L.; Zhang, Z.; Bao, Z.; Yang, Q.; Yang, Y.; Xing, H.; Ren, Q. Performance comparison of metal-organic framework extrudates and commercial zeolite for ethylene/ethane separation. Ind. Eng. Chem. Res. 2018, 57, 1645-1654. [CrossRef]

37. Krokidas, P.; Moncho, S.; Brothers, E.N.; Castier, M.; Economou, I.G. Tailoring the gas separation efficiency of metal organic framework ZIF-8 through metal substitution: A computational study. Phys. Chem. Chem. Phys. 2018, 20, 4879-4892. [CrossRef] [PubMed]

38. Chung, T.-S.; Jiang, L.Y.; Li, Y.; Kulprathipanja, S. Mixed matrix membranes (MMMs) comprising organic polymers with dispersed inorganic fillers for gas separation. Prog. Polym. Sci. 2007, 32, 483-507. [CrossRef]

39. Samarasinghe, S.; Chuah, C.Y.; Yang, Y.; Bae, T.-H. Tailoring $\mathrm{CO}_{2} / \mathrm{CH}_{4}$ separation properties of mixed-matrix membranes via combined use of two-and three-dimensional metal-organic frameworks. J. Membr. Sci. 2018, 557, 30-37. [CrossRef]

40. Mueller, R.; Hariharan, V.; Zhang, C.; Lively, R.; Vasenkov, S. Relationship between mixed and pure gas self-diffusion for ethane and ethene in ZIF-8/6FDA-DAM mixed-matrix membrane by pulsed field gradient NMR. J. Membr. Sci. 2016, 499, 12-19. [CrossRef]

41. Montoro, C.; García, E.; Calero, S.; Pérez-Fernández, M.A.; López, A.L.; Barea, E.; Navarro, J.A. Functionalisation of MOF open metal sites with pendant amines for $\mathrm{CO}_{2}$ capture. J. Mater. Chem. 2012, 22, 10155-10158. [CrossRef]

42. Planas, N.; Dzubak, A.L.; Poloni, R.; Lin, L.-C.; McManus, A.; McDonald, T.M.; Neaton, J.B.; Long, J.R.; Smit, B.; Gagliardi, L. The mechanism of carbon dioxide adsorption in an alkylamine-functionalized metal-organic framework. J. Am. Chem. Soc. 2013, 135, 7402-7405. [CrossRef]

43. Duval, J.M.; Kemperman, A.; Folkers, B.; Mulder, M.; Desgrandchamps, G.; Smolders, C. Preparation of zeolite filled glassy polymer membranes. J. Appl. Polym. Sci. 1994, 54, 409-418. [CrossRef]

44. Yang, Y.; Goh, K.; Wang, R.; Bae, T.-H. High-performance nanocomposite membranes realized by efficient molecular sieving with CuBDC nanosheets. Chem. Commun. 2017, 53, 4254-4257. [CrossRef]

45. Guücuüyener, C.; van den Bergh, J.; Gascon, J.; Kapteijn, F. Ethane/ethene separation turned on its head: Selective ethane adsorption on the metal- organic Framework ZIF-7 through a gate-opening mechanism. J. Am. Chem. Soc. 2010, 132, 17704-17706. [CrossRef] [PubMed]

46. Pires, J.O.; Pinto, M.S.L.; Saini, V.K. Ethane selective IRMOF-8 and its significance in ethane-ethylene separation by adsorption. ACS Appl. Mater. Interfaces 2014, 6, 12093-12099. [CrossRef] [PubMed]

47. Boöhme, U.; Barth, B.; Paula, C.; Kuhnt, A.; Schwieger, W.; Mundstock, A.; Caro, J.R.; Hartmann, M. Ethene/ethane and propene/propane separation via the olefin and paraffin selective metal-organic framework adsorbents CPO-27 and ZIF-8. Langmuir 2013, 29, 8592-8600. [CrossRef]

48. Chanut, N.; Bourrelly, S.; Kuchta, B.; Serre, C.; Chang, J.S.; Wright, P.A.; Llewellyn, P.L. Screening the effect of water vapour on gas adsorption performance: Application to $\mathrm{CO}_{2}$ capture from flue gas in metal-organic frameworks. ChemSusChem 2017, 10, 1543-1553. [CrossRef] [PubMed]

49. Li, W.; Chuah, C.Y.; Yang, Y.; Bae, T.-H. Nanocomposites formed by in situ growth of NiDOBDC nanoparticles on graphene oxide sheets for enhanced $\mathrm{CO}_{2}$ and $\mathrm{H}_{2}$ storage. Microporous Mesoporous Mater. 2018, 265, 35-42. [CrossRef]

50. Bae, T.H.; Lee, J.S.; Qiu, W.; Koros, W.J.; Jones, C.W.; Nair, S. A high-performance gas-separation membrane containing submicrometer-sized metal-organic framework crystals. Angew. Chem. Int. Ed. 2010, 122, 10059-10062. [CrossRef]

51. Davoodi, S.M.; Sadeghi, M.; Naghsh, M.; Moheb, A. Olefin-paraffin separation performance of polyimide Matrimid ${ }^{\circledR} /$ silica nanocomposite membranes. RSC Adv. 2016, 6, 23746-23759. [CrossRef]

52. Ploegmakers, J.; Japip, S.; Nijmeijer, K. Mixed matrix membranes containing MOFs for ethylene/ethane separation Part A: Membrane preparation and characterization. J. Membr. Sci. 2013, 428, 445-453. [CrossRef]

53. Chuah, C.Y.; Goh, K.; Bae, T.-H. Hierarchically structured HKUST-1 nanocrystals for enhanced SF 6 capture and recovery. J. Phys. Chem. C 2017, 121, 6748-6755. [CrossRef]

54. Duan, C.; Jie, X.; Liu, D.; Cao, Y.; Yuan, Q. Post-treatment effect on gas separation property of mixed matrix membranes containing metal organic frameworks. J. Membr. Sci. 2014, 466, 92-102. [CrossRef]

55. Chuah, C.Y.; Yu, S.; Na, K.; Bae, T.-H. Enhanced $\mathrm{SF}_{6}$ recovery by hierarchically structured MFI zeolite. J. Ind. Eng. Chem. 2018, 62, 64-71. [CrossRef] 
56. Myers, A.; Prausnitz, J.M. Thermodynamics of mixed-gas adsorption. AIChE J. 1965, 11, 121-127. [CrossRef]

57. Mason, J.A.; Sumida, K.; Herm, Z.R.; Krishna, R.; Long, J.R. Evaluating metal-organic frameworks for post-combustion carbon dioxide capture via temperature swing adsorption. Energy Environ. Sci. 2011, 4, 3030-3040. [CrossRef]

58. Mathias, P.M.; Kumar, R.; Moyer, J.D.; Schork, J.M.; Srinivasan, S.R.; Auvil, S.R.; Talu, O. Correlation of multicomponent gas adsorption by the dual-site Langmuir model. Application to nitrogen/oxygen adsorption on 5A-zeolite. Ind. Eng. Chem. Res. 1996, 35, 2477-2483. [CrossRef]

59. Chuah, C.Y.; Yang, Y.; Bae, T.-H. Hierarchically porous polymers containing triphenylamine for enhanced $\mathrm{SF}_{6}$ separation. Microporous Mesoporous Mater. 2018, 272, 232-240. [CrossRef]

60. Bachman, J.E.; Smith, Z.P.; Li, T.; Xu, T.; Long, J.R. Enhanced ethylene separation and plasticization resistance in polymer membranes incorporating metal-organic framework nanocrystals. Nat. Mater. 2016, 15, 845. [CrossRef] [PubMed]

61. Bereciartua, P.J.; Cantín, Á.; Corma, A.; Jordá, J.L.; Palomino, M.; Rey, F.; Valencia, S.; Corcoran, E.W.; Kortunov, P.; Ravikovitch, P.I. Control of zeolite framework flexibility and pore topology for separation of ethane and ethylene. Science 2017, 358, 1068-1071. [CrossRef]

62. Sakai, M.; Sasaki, Y.; Tomono, T.; Seshimo, M.; Matsukata, M. Olefin selective Ag-exchanged X-type zeolite membrane for propylene/propane and ethylene/ethane separation. ACS Appl. Mater. Interfaces 2019, 11, 4145-4151. [CrossRef]

63. Wee, L.H.; Lohe, M.R.; Janssens, N.; Kaskel, S.; Martens, J.A. Fine tuning of the metal-organic framework $\mathrm{Cu}_{3}(\mathrm{BTC})_{2}$ HKUST-1 crystal size in the $100 \mathrm{~nm}$ to 5 micron range. J. Mater. Chem. 2012, 22, 13742-13746. [CrossRef]

64. Xin, C.; Zhan, H.; Huang, X.; Li, H.; Zhao, N.; Xiao, F.; Wei, W.; Sun, Y. Effect of various alkaline agents on the size and morphology of nano-sized HKUST-1 for $\mathrm{CO}_{2}$ adsorption. RSC Adv. 2015, 5, 27901-27911. [CrossRef]

65. Loera-Serna, S.; Solis, H.; Ortiz, E.; Martínez-Hernandéz, A.; Noreña, L. Elimination of Methylene Blue and Reactive Black 5 from Aqueous Solution Using HKUST-1. Ind. J. Environ. Sci. Dev. 2017, 8, 241. [CrossRef]

66. Chuah, C.Y.; Bae, T.-H. Incorporation of $\mathrm{Cu}_{3} \mathrm{BTC}_{2}$ nanocrystals to increase the permeability of polymeric membranes in $\mathrm{O}_{2} / \mathrm{N}_{2}$ separation. BMC Chem. Eng. 2019, 1, 2. [CrossRef]

67. Li, J.-R.; Kuppler, R.J.; Zhou, H.-C. Selective gas adsorption and separation in metal-organic frameworks. Chem. Soc. Rev. 2009, 38, 1477-1504. [CrossRef] [PubMed]

68. Geier, S.J.; Mason, J.A.; Bloch, E.D.; Queen, W.L.; Hudson, M.R.; Brown, C.M.; Long, J.R. Selective adsorption of ethylene over ethane and propylene over propane in the metal-organic frameworks $\mathrm{M}_{2}(\mathrm{dobdc})(\mathrm{M}=\mathrm{Mg}$, Mn, Fe, Co, Ni, Zn). Chem. Sci. 2013, 4, 2054-2061. [CrossRef]

69. Ziegler, T.; Rauk, A. A theoretical study of the ethylene-metal bond in complexes between copper $(1+)$, silver $(1+)$, gold $(1+)$, platinum (0) or platinum $(2+)$ and ethylene, based on the Hartree-Fock-Slater transition-state method. Inorg. Chem. 1979, 18, 1558-1565. [CrossRef]

70. Li, W.; Samarasinghe, S.; Bae, T.-H. Enhancing $\mathrm{CO}_{2} / \mathrm{CH}_{4}$ separation performance and mechanical strength of mixed-matrix membrane via combined use of graphene oxide and ZIF-8. J. Ind. Eng. Chem. 2018, 67, 156-163. [CrossRef]

71. Samarasinghe, S.; Chuah, C.Y.; Li, W.; Sethunga, G.; Wang, R.; Bae, T.-H. Incorporation of Co ${ }^{\text {III }}$ acetylacetonate and SNW-1 nanoparticles to tailor $\mathrm{O}_{2} / \mathrm{N}_{2}$ separation performance of mixed-matrix membrane. Sep. Purif. Technol. 2019, 223, 133-141. [CrossRef]

72. Fernández-Barquín, A.; Casado-Coterillo, C.; Palomino, M.; Valencia, S.; Irabien, A. LTA/Poly (1-trimethylsilyl-1-propyne) Mixed-Matrix Membranes for High-Temperature $\mathrm{CO}_{2} / \mathrm{N}_{2}$ Separation. Chem. Eng. Technol. 2015, 38, 658-666. [CrossRef]

73. Li, W.; Chuah, C.Y.; Nie, L.; Bae, T.-H. Enhanced $\mathrm{CO}_{2} / \mathrm{CH}_{4}$ selectivity and mechanical strength of mixed-matrix membrane incorporated with NiDOBDC/GO composite. J. Ind. Eng. Chem. 2019, 74, 118-125. [CrossRef]

74. Goh, P.; Ismail, A.; Sanip, S.; Ng, B.; Aziz, M. Recent advances of inorganic fillers in mixed matrix membrane for gas separation. Sep. Purif. Technol. 2011, 81, 243-264. [CrossRef]

75. Gong, H.; Nguyen, T.H.; Wang, R.; Bae, T.-H. Separations of binary mixtures of $\mathrm{CO}_{2} / \mathrm{CH}_{4}$ and $\mathrm{CO}_{2} / \mathrm{N}_{2}$ with mixed-matrix membranes containing $\mathrm{Zn}\left(\mathrm{pyrz}_{2}\left(\mathrm{SiF}_{6}\right)\right.$ metal-organic framework. J. Membr. Sci. 2015, 495, 169-175. [CrossRef] 
76. Ge, L.; Zhou, W.; Rudolph, V.; Zhu, Z. Mixed matrix membranes incorporated with size-reduced Cu-BTC for improved gas separation. J. Mater. Chem. A 2013, 1, 6350-6358. [CrossRef]

77. Zhang, C.; Lively, R.P.; Zhang, K.; Johnson, J.R.; Karvan, O.; Koros, W.J. Unexpected molecular sieving properties of zeolitic imidazolate framework-8. J. Phys. Chem. Lett. 2012, 3, 2130-2134. [CrossRef] [PubMed]

(C) 2020 by the authors. Licensee MDPI, Basel, Switzerland. This article is an open access article distributed under the terms and conditions of the Creative Commons Attribution (CC BY) license (http://creativecommons.org/licenses/by/4.0/). 